\title{
Microwave pyrolysis using self-generated pyrolysis gas as activating agent: An innovative single-step approach to convert waste palm shell into activated carbon
}

\author{
Peter Nai Yuh Yek ${ }^{1,2}$, Rock Keey Liew ${ }^{2}$, Mohammad Shahril Osman ${ }^{1}$, Chee Chung Wong ${ }^{1}$, \\ and Su Shiung Lam ${ }^{2, *}$
}

${ }^{1}$ University College of Technology Sarawak, Department of Engineering, 96000, Sibu, Sarawak, Malaysia

${ }^{2}$ Pyrolysis Technology Research Group, Eastern Corridor Renewable Energy Group (ECRE), School of Ocean Engineering, Universiti Malaysia Terengganu, 21030 Kuala Terengganu, Terengganu,

Malaysia

\begin{abstract}
Waste palm shell (WPS) is a biomass residue largely available from palm oil industries. An innovative microwave pyrolysis method was developed to produce biochar from WPS while the pyrolysis gas generated as another product is simultaneously used as activating agent to transform the biochar into waste palm shell activated carbon (WPSAC), thus allowing carbonization and activation to be performed simultaneously in a single-step approach. The pyrolysis method was investigated over a range of process temperature and feedstock amount with emphasis on the yield and composition of the WPSAC obtained. The WPSAC was tested as dye adsorbent in removing methylene blue. This pyrolysis approach provided a fast heating rate $\left(37.5^{\circ} \mathrm{C} / \mathrm{min}\right)$ and short process time $(20 \mathrm{~min})$ in transforming WPS into WPSAC, recording a product yield of $40 \mathrm{wt} \%$. The WPSAC was detected with high BET surface area $\left(\geq 1200 \mathrm{~m}^{2} / \mathrm{g}\right)$, low ash content $(<5 \mathrm{wt} \%)$, and high pore volume $\left(\geq 0.54 \mathrm{~cm}^{3} / \mathrm{g}\right)$, thus recording high adsorption efficiency of $440 \mathrm{mg}$ of dye/g. The desirable process features (fast heating rate, short process time) and the recovery of WPSAC suggest the exceptional promise of the single-step microwave pyrolysis approach to produce high-grade WPSAC from WPS.
\end{abstract}

\section{Introduction}

Palm oil represents one of the main agriculture commodity in Malaysia, recording approximately 17 million tons of production in 2016 [1]. Consequently, nearly 53 million tons of wastes palm have been generated every year from the palm oil industry [2]. Each ton of oil palm wastes consists mainly of $22 \mathrm{wt} \%$ of empty fruit bunch (EFB), $6 \mathrm{wt} \%$ of waste palm shell (WPS) and $14 \mathrm{wt} \%$ of palm mesocarp fibre (PMF). These wastes are

\footnotetext{
*Corresponding author: lam@umt.edu.my
} 
currently under-utilized and simply burned as solid fuel in boiler to generate steam for sterilization. The current practice emits undesirable fly ash and greenhouse gas to the atmosphere which in turn creates environmental pollution. Therefore, oil palm wastes should be converted into useful products such as activated carbon in order to maximize its economic value rather than using it as boiler fuels.

Waste palm shell activated carbon (WPSAC) is a carbonaceous material produced from controlled thermal process in order to increase the level of porosity by high internal surface area and pore volume. The performance of WPSAC is determined by pore size (e.g. microporous, mesoporous, or macroporous) and surface composition (e.g. the presence of oxygen or acidic functional group) influences the adsorption efficiency [3]. Due to these properties, WPSAC has widely been applied in removal or adsorption of carbon dioxide from the exhaust gas streams in power plant and the raw natural gas in agriculture industry [4], removal of phenol [5] and tetracycline [6] in chemical industry, or used as adsorbent to remove heavy metals such as lead $(\mathrm{Pb})$ and cadmium $(\mathrm{Cd})$ [7]. Recently, WPSAC was utilized in technological applications such as supercapacitor and protection from electromagnetic radiation $[8,9]$.

The present study attempts to utilize an innovative single step approach to produce WPSAC from waste palm shell by microwave pyrolysis using self generated $\mathrm{CO}_{2}$ as activating agent. Microwave radiation as a heat source provide rapid and targeted heating to the inside waste palm shell by dipole rotation and ionic conduction [10]. The study also examined the influence from varying the amount of waste palm shell as feedstock and the pyrolysis temperature on the process features, the yield and composition of the WPSAC obtained, and its adsorption of methylene blue. These features are important to assess the feasibility of developing a single step method that is energy and cost efficient in producing WPSAC from oil palm waste. There have been limited studies on single step physical activation of WPSAC preparation, and no studies have been reported on the use of self-generated pyrolysis gas for WPSAC preparation via microwave pyrolysis technique.

\section{Material and methods}

\subsection{Source and preparation of waste palm shell}

Waste palm shell (WPS) was collected from a palm oil mill located in Sibu, Sarawak. The waste was washed with distilled water to remove dust and impurities. It was then dried in the oven at $110^{\circ} \mathrm{C}$ for 2 hours to remove moisture and ground to a desired size of $0.15 \mathrm{~mm}$ for further analysis.

\subsection{Characterization of WPS}

WPS was analysed using proximate and ultimate analyses. The proximate analysis was conducted according to the ASTM standards D5142 to determine the contents of moisture, fixed carbon, volatile matter, and ash. Elemental analysis was conducted using a FlashEA 1112 CHNS elemental analyser to determine the carbon, hydrogen, nitrogen and sulphur contents in the WPS, whereas the oxygen content was determined by mass difference. 


\subsection{Microwave pyrolysis of WPS}

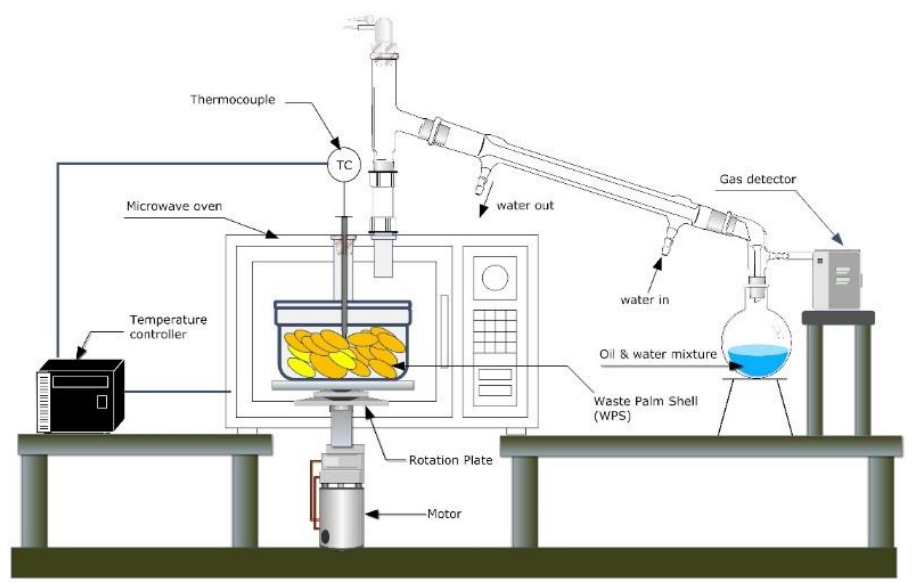

Fig. 1. Schematic diagram of microwave pyrolysis system used to produce activated carbon.

Fig. 1 shows the schematic diagram of the microwave pyrolysis system. Pyrolysis of WPS was performed in a modified microwave oven (Sharp R213CST) with a frequency of $2450 \mathrm{MHz}$. The microwave oven housed a porcelain reactor that can prevent combustion in the reactor. The pyrolysis experiments were performed in batch and closed operation, and a rotation plate was used to ensure even distribution of microwave irradiation. A Type-K thermocouple was used to measure the temperature and the readings were recorded by a data logger every 5 seconds throughout the pyrolysis process. A gas detector was placed near to the exhaust point to determine the presence of hydrocarbon, $\mathrm{CO}$ and $\mathrm{CO}_{2}$ gases in the pyrolysis gas produced after the pyrolysis operation.

The experiment started by inserting different amounts of WPS into the reactor. Then, the microwave oven was turned on to heat and pyrolyze the WPS for $35 \mathrm{~min}$ at $900 \mathrm{~W}$ with a rotation speed of $10 \mathrm{rpm}$. The waste palm activated carbon (WPSAC) was produced as the main product of interest and it was cooled down inside the ceramics reactor. The product yield was calculated based on the equation 1 , where $\mathrm{Y}$ is the mass yield, $\mathrm{m}_{\mathrm{i}}$ and $\mathrm{m}_{\mathrm{f}}$ refer to the initial mass and final mass respectively. WPSAC was washed using distilled water and dried in an oven at $105^{\circ} \mathrm{C}$. The dried WPSAC was stored for analyses and future use.

$$
Y=\frac{m_{i}}{m f} \times 100 \%
$$

\subsection{Single step activation}

$$
\begin{gathered}
\mathrm{C}+\mathrm{H}_{2} \mathrm{O} \rightarrow \mathrm{H}_{2}+\mathrm{CO} \\
\mathrm{CO}+\mathrm{H}_{2} \mathrm{O} \rightarrow \mathrm{H}_{2}+\mathrm{CO}_{2} \\
\mathrm{C}+2 \mathrm{H}_{2} \rightarrow \mathrm{CH}_{4} \\
\mathrm{C}+\mathrm{CO}_{2} \rightarrow 2 \mathrm{CO}
\end{gathered}
$$

During carbonization stage, WPS was heated and pyrolyzed and this resulted in the release of volatile matter in the form of pyrolysis gas and the generation of pores on the surface of the solid char formed during the microwave pyrolysis process. The pyrolysis gas was remained in the reactor and this in turn contributed to activation of the solid char to produce 
more mores on its surface, thus producing a highly porous solid char termed "activated carbon". The WPS was converted into WPSAC via one step activation by self-generated pyrolysis gas in which the carbonization and activation occurred simultaneously. Heating in the closed system of ceramics reactor, the moisture $\left(\mathrm{H}_{2} \mathrm{O}\right)$ content of WPS was likely to evaporate as hot gas and WPS has carbonized by microwave pyrolysis to become hot char. Reaction between hot char of WPS and hot gas generated hydrogen gas and carbon monoxide (Equation 2). Carbon monoxide as one of the product from Eqn. 2 was further reacted with $\mathrm{H}_{2} \mathrm{O}$ to produce more hydrogen and carbon dioxide (Equation 3). Both products (i.e. $\mathrm{CO}_{2}$ and $\mathrm{H}_{2}$ ) obtained from Eqn. 3 were reacted with hot char to produce methane gas and carbon monoxide as shown in Equation 4 and 5, respectively. Activation process occurred during reaction between carbon dioxide with hot char as shown in Eqn 4.

\subsection{Characterization of waste palm activated carbon}

The WPSAC was analysed for their chemical functional group using a Perkin Elmer Spectrum 100 Fourier Transform Infrared (FTIR) spectrometer. A thin KBr (potassium bromide) disc method was used in the FTIR analysis. The analysis was then performed at wavenumber ranging from 400 to $4000 \mathrm{~cm}^{-1}$ for each sample [11]. The infrared spectrum obtained was presented in a form of transmittance (\%) against wavenumber $\left(\mathrm{cm}^{-1}\right)$.

Scanning electron microscopy (SEM) analysis of WPSAC was conducted using JEOL JCM6000 to study the surface morphology and porosity. The WPSAC was also characterized using an accelerated surface area and porosimetry system (ASAP 2010, Micromeritics) to obtain $\mathrm{N}_{2}$ adsorption-desorption isotherm for calculation of BET surface area, pore volume and pore size.

\subsection{Adsorption test of methylene blue using WPSAC}

The adsorption test of methylene blue (MB) was conducted using the WPSAC obtained. The adsorption test was performed in a beaker containing $0.5 \mathrm{~g}$ of WPSAC and $300 \mathrm{~mL}$ of methylene blue solution with an initial concentration of $10 \mathrm{mg} / \mathrm{L}$. The beaker was agitated at room temperature with a mixer speed of $200 \mathrm{rpm}$ until the equilibrium was reached. The methylene blue solution was centrifuged and the residual concentration of $\mathrm{MB}$ in the supernatant solution was analysed using a UV-Vis spectrophotometer at $665 \mathrm{~nm}$. The amount of $\mathrm{MB}$ adsorbed per unit mass of adsorbent at equilibrium, $\mathrm{q}_{\mathrm{e}}(\mathrm{mg} / \mathrm{g})$, was calculated by:

$$
q_{e}=\frac{\left(C_{o}-C_{e}\right) V}{W}
$$

where $C_{0}$ and $C_{e}(\mathrm{mg} / \mathrm{L})$ are the liquid-phase concentrations of dye at initial and equilibrium, respectively. $\mathrm{V}$ is the volume of the solution in litre, and $\mathrm{W}$ is the mass of adsorbent used in gram. 


\section{Results and discussions}

\subsection{Proximate and elemental analyses of waste palm shell}

Table 1. Proximate analysis (wt $\%)$ and Elemental analysis (wt $\%)$

\begin{tabular}{|c|c|c|}
\hline Description & Waste palm shell (WPS) & $\begin{array}{c}\text { Waste palm shell activated } \\
\text { carbon (WPSAC) }\end{array}$ \\
\hline \multicolumn{3}{|c|}{ Proximate analysis (wt\%) } \\
\hline Moisture $^{\mathrm{a}}$ & 4 & 2 \\
\hline Volatile matter $^{\mathrm{b}}$ & 58 & 10 \\
\hline Fixed carbon $^{\mathrm{c}}$ & 34 & 85 \\
\hline $\operatorname{Ash}^{\mathrm{d}}$ & 4 & 3 \\
\hline \multicolumn{3}{|c|}{ Elemental analysis (wt\%) } \\
\hline Carbon & 50.5 & 82.8 \\
\hline Hydrogen & 6.9 & 4.1 \\
\hline Nitrogen & 3.1 & 2.8 \\
\hline Sulfur & 0.1 & 0.1 \\
\hline Oyxgen $^{c}$ & 39.4 & 10.2 \\
\hline
\end{tabular}

${ }^{a}$ Dry basis

b Volatile matter produced from pyrolytic decomposition of hemicellulose, cellulose, and lignin

${ }^{c}$ Calculated by difference

${ }^{\mathrm{d}}$ Obtained by combustion at $1000^{\circ} \mathrm{C}$

Table 1 shows the proximate and elemental composition of WPS and WPSAC. The WPS was dominated by volatile matter $(58 \mathrm{wt} \%)$ and fixed carbon $(34 \mathrm{wt} \%)$ with small amounts of moisture (4 wt $\%)$ and ash (4 wt $\%)$. The high volatile content suggests that WPS is more likely to be reactive in creating more pores on the carbonaceous material formed from pyrolytic carbonization process [12]. The WPS can be pyrolyzed to produce carbon rich material such as biochar or activated carbon due to its considerable amount of fixed carbon. As shown in Table 1, the fixed carbon, volatiles, moisture and ash content for the resulting WPSAC was $85 \mathrm{wt} \%, 10 \mathrm{wt} \%, 2 \mathrm{wt} \%$ and $3 \mathrm{wt} \%$, respectively. This indicates that the carbonization of WPS during microwave pyrolysis had reduced the volatile matter of WPSAC to $10 \%$ and increased the fixed carbon content to $85 \%$. Relatively high fixed carbon and low ash contents make WPS more profitable if compare to other palm biomass to produce higher yield of WPSAC. It was also found from Table 1 that the carbon content of WPSAC was increased to $82.8 \mathrm{wt} \%$, and the content of oxygen reduced to $10.2 \mathrm{wt} \%$ with small amount of hydrogen (6.9 wt $\%)$, nitrogen $(3.1 \mathrm{wt} \%)$ and sulfur $(0.1 \mathrm{wt} \%)$. Overall, the results from proximate and elemental analysis indicate that the microwave pyrolysis transformed WPS into a carbon rich material with properties comparable to biochar. 


\subsection{Chemical functional groups of waste palm shell activated carbon}

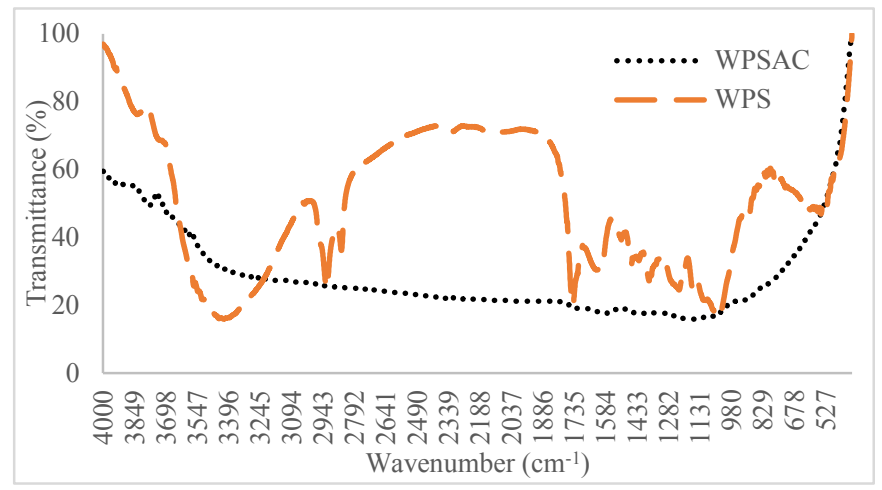

Fig. 2. FTIR spectrum of raw waste palm shell (WPS) and waste palm shell activated carbon (WPSAC).

The FTIR spectra of raw WPS and WPSAC are shown in Fig 2. The spectra of the WPS displayed the following bands 3200-3600 which correspond to $\mathrm{O}-\mathrm{H}$ stretch in alcohols; $1400-1600$ which is assigned to $\mathrm{C}=\mathrm{C}$ stretch aromatics; the bands at $1000-1300$ could be related to C-O groups. Raw WPS showing a wide range of transmittance peak, indicated that a large amount of organic and inorganic matters from cellulose, hemicellulose and lignin. Compare to the almost flat FTIR spectra of WPSAC, indicated that almost all the lignocellulose materials were completely decomposed during carbonization and activation process [13]. Spectra showed great difference at bands 3200-3600 which directly indicates that hydrogen was broadly removed to form graphitic structure; a typical activated carbon structure. However, WPSAC also showing transmittance peak at $1590 \mathrm{~cm}^{-1}$ related to functional group of aromatic with $\mathrm{C}=\mathrm{C}$ stretch bending that cause higher reactions in the methylene blue absorption later.

\subsection{Temperature profile of different feedstock amount}

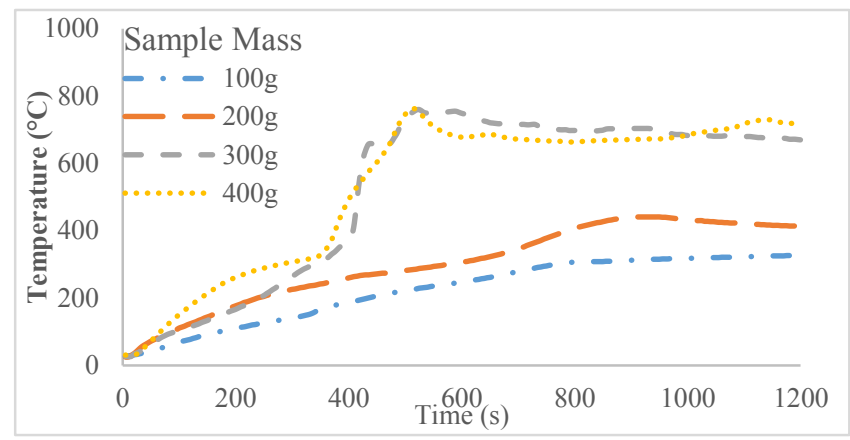

Fig. 3. Temperature profiles for pyrolysis of WPSAC obtained from different feedstock amount.

Fig. 3 shows temperature profiles recorded during pyrolysis of the waste palm shell with different sample mass. It can be observed that comparatively lower temperatures were achieved for 100 and $200 \mathrm{~g}$ of sample mass with maximum temperature recorded at $330^{\circ} \mathrm{C}$ and $450^{\circ} \mathrm{C}$ respectively. However, when sample mass was increased to $300 \mathrm{~g}$ and $400 \mathrm{~g}$, the maximum temperature achieved was increased significantly to $750^{\circ} \mathrm{C}$ at around $500 \mathrm{~s}$. This 
was probably because more carbon monoxide and hydrogen generated from the exothermic reaction in Eq 3 and 4. Also, exothermic reaction in more feedstock (300 g and $400 \mathrm{~g}$ ) is much larger than endothermic reaction (Eq. 2 and 5). Then, more heat energy released to cause rapid increasing of temperature from 300 to $750^{\circ} \mathrm{C}$ in 300 and $400 \mathrm{~g}$ feedstock amount.

Generally, pyrolysis of the biomass was observed to produce biochar, bio-oil vapours, steam, and incondensable gases as by-products. The incondensable gases could consist of high amounts $\mathrm{CO}$ and small amounts of $\mathrm{H}_{2}$ and $\mathrm{CO}_{2}$, which form pyrolysis gas [14]. In this research, it was thought that the pyrolysis gas produced within the reactor was trapped inside the ceramics reactor and forced to react with hot char and caused exothermic reaction. Besides that, hot char also carried out activation by carbon dioxide shown in Equation 5 as majority carbon monoxide and with minor gases of hydrogen and carbon dioxide were detected by gas alert at gas emission channel. When the pyrolysis temperature was further increased above $450^{\circ} \mathrm{C}$, softening and decomposition of the high-molecularweight compounds occurred that resulted from the depolymerisation of lignocellulosic components such as lignin [15].

\subsection{Yields, surface area and adsorption performance of waste palm shell activated carbon}

Table 2. Yields, surface area and adsorption performance of waste palm shell activated carbon.

\begin{tabular}{|c|c|c|c|c|}
\hline $\begin{array}{c}\text { Sample mass } \\
(\mathrm{g})\end{array}$ & $\begin{array}{c}\text { Maximum } \\
\text { Temperature }\left({ }^{\circ} \mathrm{C}\right)\end{array}$ & Yields $(\mathrm{wt} \%)$ & S $\mathrm{BET}\left(\mathrm{m}^{2} / \mathrm{g}\right)$ & $\begin{array}{c}\text { MB adsorption } \\
(\mathrm{mg} / \mathrm{g})\end{array}$ \\
\hline 100 & 330 & 43.0 & 750 & 160 \\
\hline 200 & 450 & 35.5 & 890 & 250 \\
\hline 300 & 750 & 31.5 & 1200 & 425 \\
\hline 400 & 750 & 31.0 & 1252 & 440 \\
\hline
\end{tabular}

Table 2 shows the yield of WPSAC obtained at different maximum temperature and feedstock amount. The reaction rate in pyrolysis can be expressed in terms of conversion from the raw waste palm shell to WPSAC The conversion (C) of pyrolysis is defined as the ratio of weight loss to the initial raw material weight shown in the Eq. 7,

$$
C=\frac{m_{i}-m_{t}}{m_{i}}
$$

where $m_{i}$ is the weight of the initial raw material (WPS) and $m_{t}$ is the weight of char after pyrolysis. In this respect, the weight loss of the sample or the conversion is an indication of the thermal degradation occurring during pyrolysis. Higher pyrolysis temperature contributed immensely to the volatilization of cellulose, hemicelluloses and lignin which may be responsible for the low WPSAC yield [15].

The release of the volatiles from the carbon structures of the waste palm shell is dependent on the prevailing pyrolysis temperature. At about $450{ }^{\circ} \mathrm{C}$, low molecular - weight volatiles are released, thereby WPSAC yields with around $35.5 \%$ to $43.0 \mathrm{wt} \%$ (Table 1 ). Further increases in the pyrolysis temperature to $750^{\circ} \mathrm{C}$, the small gradual decrease of yields to $31.0 \mathrm{wt} \%$ caused by the releasing of high-molecular-weight volatiles. Beyond that, the release of volatiles is almost complete and hence the conversion remains constant. The produced WPSAC had tested as absorbent for Methylene blue adsorption test. The removal of Methylene blue increased with prolonging the contact time to 24 hours and reached the equilibrium stage. The amount of $\mathrm{MB}$ adsorbed at the equilibrium time reflects the maximum adsorption uptake of WPSAC under operating conditions. In the present study, 
adsorption equilibrium, $\mathrm{q}_{\mathrm{e}}$ reached $440 \mathrm{mg} / \mathrm{g}$ with an initial concentration of $10 \mathrm{mg} / \mathrm{L}$.

\subsection{Textural and surface morphology}

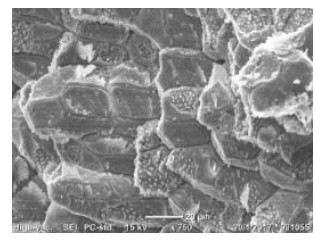

Fig. 4. Raw waste palm shell.

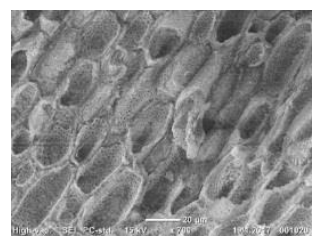

Fig. 5. Uniform pore in $100 \mathrm{~g}$.

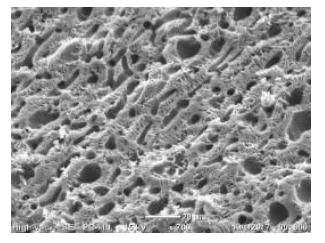

Fig. 6. Irregular pore sizes in $200 \mathrm{~g}$.

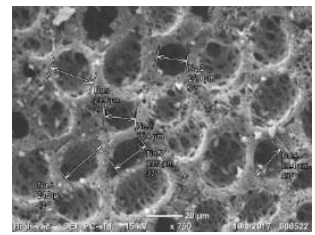

Fig. 7. Uniform macro pore in $300 \mathrm{~g}$ and $400 \mathrm{~g}$.

The scanning electron micrograph shows the pores development on the surface of the WPS to WPSAC. WPS is covered with many globular silica bodies that contain sharp, conical agglomerations shown in Fig. 4 [16]. During microwave pyrolysis, silica body was removed from the carbon surface and create a macro pore shown in Fig. 5. With 100 gram of WPS loading and maximum temperature of $330^{\circ} \mathrm{C}$, pores with less than $1 \mu \mathrm{m}$ have been observed on waste palm biochar due to releasing globular silica body from the WPS surface. However, Fig. 6 observed some porous structure with non-regular pore sizes developed on the surface. This is probably due to decomposition of hemicellulose happen when maximum temperature reached $450^{\circ} \mathrm{C}$ in $200 \mathrm{~g}$ WPS sample. Fig. 7 shown the effect of pyrolysis temperature appears on the larger pores generated and within it some smaller pores generated by pyrolysis gas activation. The pores on the surface of the WPSAC are well-developed with mainly 2 types of macrospore. Larger pores size range from 15-25 $\mu \mathrm{m}$ and within it some smaller pores ranging from $1-5 \mu \mathrm{m}$ are generated with activation 
process. Due to this, larger surface area generated and better for the adsorption.

\section{Conclusion}

In this study, waste palm shell-based activated carbons were produced successfully by self-generated pyrolysis gas as activating agent. From the experiment, quantity of WPS as one of the factor influence the generation of pyrolysis gas to perform the activation. Single-step approach reduced the production cost and time to convert waste palm shell into activated carbon. The results of the present investigation show that WPSAC prepared is potential useful adsorbent for the MB adsorption.

The authors gratefully acknowledge the financial support provided by University College of Technology Sarawak under Grant scheme (Project No.

UCTS/RESEARCH/<1/2016/03>(01)).

\section{References}

1. C.Y. May, Overview of the Malaysian Oil Palm Industry, Malaysian Palm Oil Board, Economics \& Industry Development Division, 2016

2. J.P. Tang, H.L. Lam, M.K. Abdul Aziz, N.A. Morad. Energ.

3. S. Sedghi, S.H. Madani, C. Hu, A. Silvestre-Albero, W. Skinner, P. Kwong, P. Pendleton, R.J. Smernik, F. Rodríguez-Reinoso, M.J. Biggs. Carbon 95, 144-149 (2015)

4. M.K. Aroua, W.M.A.W. Daud, C.Y. Yin, D. Adinata. Sep. Purif. Technol. 62, 609-613 (2008)

5. S. Mubarik, A. Saeed, M.M. Athar, M. Iqbal. J. Ind. Eng. Chem. 33, 115-121 (2016)

6. P. Liu, W.-J. Liu, H. Jiang, J.-J. Chen, W.-W. Li, H.-Q. Yu. Bioresour. Technol. 121, 235-240 (2012)

7. P. Xu, C.-X. Sun, X.-Z. Ye, W.-D. Xiao, Q. Zhang, Q. Wang. Ecotoxicol. Environ. Saf. 132, 94-100 (2016)

8. R.K. Gupta, M. Dubey, P. Kharel, Z. Gu, Q.H. Fan. J. Power Sources 274, 1300-1305 (2015)

9. M. Tripathi, J.N. Sahu, P. Ganesan, J. Jewaratnam. Appl. Thermal Eng. 105, 605-612 (2016)

10. S.S. Lam, R.K. Liew, C.K. Cheng, H.A. Chase. Appl. Catal. B-Environ. 176-177, 601-617 (2015)

11. S.S. Lam, R.K. Liew, X.Y. Lim, F.N. Ani, A. Jusoh. Int. Biodeter. Biodeg. 113, 325-333 (2016)

12. S.S. Idris, N.A. Rahman, K. Ismail, A.B. Alias, Z.A. Rashid, M.J. Aris. Bioresour. Technol. 101, 4584-4592 (2010)

13. A.F. Rugayah, A.A. Astimar, N. Norzita. J. Oil Palm Res. 26, 251-264 (2014)

14. H. Guo, F. Peng, H. Zhang, L. Xiong, S. Li, C. Wang, B. Wang, X. Chen, Y. Chen. Int. J. Hydrogen Energ. 39, 9200-9211 (2014)

15. Q. Jia, A.C. Lua. J. Anal. Appl. Pyrol. 83, 175-179 (2008)

16. A.M. Abioye, F.N. Ani. Appl. Mech. Mater. 695, 12-15 (2014) 